\title{
Methods of Forecasting and Occurrence of Traumatic Damages i Sport
}

\author{
Sulaymanov Sunnatulla Sulaymonovich, Mudarisova Rayxon Hodjaevna, Narziev Shovkiddin \\ Murtazaevich, Valieva Zaynab Omonbaevna, Tursunova Nigora Anvarovna
}

\begin{abstract}
The article analyzes the main causes of injuries sustained by athletes as a result of unsuccessful sports events, outdated sports equipment and equipment, as well as noncompliance with sports rules. In addition, the conclusions from the research results on the research topic are summarized.
\end{abstract}

Keywords: Trauma in sports, sports, head and face injuries, elbow joint, knee joint, rules, methods of prediction, safety, innovation

\section{INTRODUCTION}

Uzbekistan is known today as a country where prominent international sports competitions are held. International sports competitions are held at the modern sports complexes on football, basketball, weightlifting, heavy athletics, tennis, gymnastics, rhythmic gymnastics and other sports.

In a short time the organizational basis for managing the physical culture and sports was improved, the National Olympic Committee of Uzbekistan, the Republican Federations of Sports has been established.

The Fund for the Development of Children's Sports has been established in our country, the Fund has established new sports facilities in various regions of our country. The sports complexes were equipped with the necessary equipment $[1,2,3]$.

Long-term research on the location of injuries in athletes helps to identify the weakest links in the locomotive apparatus. In the scientific literature (VKDobrovolskiy, 1962, Z.S.Mironova, 1964, 1968), as it has been described many times, the knee joint is currently the weakest link and its share is $50 \%$ of the basic motor pathology. The next one is the retrograde joints. Her injuries and illnesses are reported in $10 \%$ of athletes. Approximately $10 \%$ of the pelvic infarction pathology is associated with the breast and waist circumference [4,5].

Specifically, the percentage of acute injuries and chronic diseases of the musculoskeletal system differed in the same group of patients who weighed: $61 \%$ of the injuries and $39 \%$ of the disease. This data confirms the results of many statistical surveys by authors (v.i.rokityanskiy, 1964; lmdorkin, 1964) [4,5].

Revised Manuscript Received on July 18, 2019.

Sulaymanov Sunnatulla Sulaymonovich, doctor of technical sciences, professor, Tashkent Institute of Railway Engineering, Tashkent, Uzbekistan

Mudarisova Rayxon Hodjaevna, candidate of medical sciences, associate professor, Uzbek State World Languages University, Tashkent, Uzbekistan

Narziev Shovkiddin Murtazaevich, Senior Teacher - Tashkent State Technical University, Tashkent, Uzbekistan.

Valieva Zaynab Omonbaevna, Senior teacher - Uzbek State World Languages University, Tashkent, Uzbekistan.

Tursunova Nigora Anvarovna, teacher - Uzbek State World Languages University, Tashkent, Uzbekistan.
At the same time, the results of the research conducted by v.fashkirov contradict the data of n.n.priorov (1958), l.lakova (1958), d.shoviev (1981). They found a significant difference in the number of chronic microtravines in the opposite tissue. Probably it is explained that different authors work with different contingencies $[4,5]$.

\section{THE MAIN HYPOTHESIS OF THE RESEARCH \& RESULTS}

Defining, applying and executing requirements for sports rules, training requirements, requirements for sports facilities microclimate and sanitary-hygienic requirements for weather conditions, technical requirements for sports equipment and equipment, requirements of labor protection and safety normative-legal acts , creating and applying innovative solutions to prevent injuries and mitigate the consequences of the injury, or to reduce or eliminate sports injuries.

Injuries in sports depend on type of sports. In boxing, wrestling, kurash, weightlifting, gymnastics and muscle injuries are more common. Sports, athletics (jump, jumping, throwing), gymnastics and wrestling often result in bone fractures.

In most sports, legs are also damaged. For example, leg injuries in light athletics and wrestling are 66\%. Boxers suffer more head and face injury (65\%), basketball and volleyball players $(80 \%)$, cufflinks, tennis players and young gymnasts (70\%) - elbow joints, and players with knee joint injury (48\%). Light injuries are more frequent in sports injury $(90 \%)$. The severity of sport injuries depends on sports types [4,5].

The mechanism of injury often defines the characteristics of the injury and the severity of the injury. The country is facing the need to develop sports, to identify the causes of injury during sports training, to study the conditions of their occurrence and to select, to create and apply innovative scientific solutions.

All causes of injuries in sports can be conditional on external and internal causes. External factors: misuse of teaching methods. At the same time, the training technique breaks the sport.

The reason is that there is no reasonably well-organized exercise, and in the short run, it is important not to take measures to accelerate the post-fitness and post-delivery recovery efforts to achieve high sport results. Failure to comply with the instruction and discipline of the exercise training, as well as the breach of safety rules, ignoring them will play a role in the origin of such injuries. 


\begin{tabular}{|c|c|c|}
\hline No & Causes of Sports Damage & Comments \\
\hline 1. & Incorrect plasement of athletes & $\begin{array}{l}\text { The greater the number of athletes and spectators in plases of training. } \\
\text { At the same time, a wrestling game, as well as boxing, karate, sambo, } \\
\text { Greco-Roman wrestling and other sports trainings, safety rules are } \\
\text { incomplate and non-compliance }\end{array}$ \\
\hline 2. & $\begin{array}{l}\text { Incorrect pairing, sorting, } \\
\text { substitution, training quality } \\
\text { control exercises by participarts } \\
\text { in sporting exercises }\end{array}$ & $\begin{array}{l}\text { Participation in sports trainings, physical training, sports qualifications, } \\
\text { age, sex and weight (in kurssh and boxing, mistakes in teamwork, } \\
\text { training sessions without trainers, number of trainees under } \\
\text { supervision, compliance with safety rules lack of control }\end{array}$ \\
\hline 3. & $\begin{array}{l}\text { Damage to sports facilities, } \\
\text { equipment for which sporting } \\
\text { exercises are to be carried out, } \\
\text { their inadequacy }\end{array}$ & $\begin{array}{l}\text { Non-adherencato hygienic and material andtechnical rulas of sports } \\
\text { equipment, sports facilites, spoting goods and equipment (clothing, } \\
\text { footwear, protective equipment), place of training, as well as non- } \\
\text { adherenceto equipment, playgrounds, halls, rules of uss of equipment } \\
\text { and sports facilities do not. The area of training, the lack of smooth } \\
\text { running surfares, thelack of slipping of the floor lid, and others may } \\
\text { cause injury. }\end{array}$ \\
\hline 4. & $\begin{array}{l}\text { Conducting sports training in } \\
\text { dissdvantagedmicroclimatic } \\
\text { and weather conditions }\end{array}$ & $\begin{array}{l}\text { Unsatisfactory sanitary-hygienic condition of sports facilities, } \\
\text { illumination, relative humidity, temperature, speed of movement, } \\
\text { temperature of drinking water, operation of ventilation system, non- } \\
\text { observance of hygienic standards on harmful factors and others }\end{array}$ \\
\hline
\end{tabular}

Table 1 Causes of Sports injuries

The wrong actions of athletes also causes injury. This is primarily due to haste, neglect, and lack of discipline. The cause of injury is to commit grossly prohibited actions against athletes. This is often the case with injuries. There is a need for extensive educational work among athletes.

Failure to adhere to doctor's prescription when organizing a learning exercise can also lead to injuries. Do not follow the doctor's recommendations to allow the practitioners to participate without a doctor's exam in their studies, do not follow the doctor's recommendations by the trainers and the athlete, to incorrectly incorporate the students into the medical team for physical training and to increase the work ability of the athletes, prevent the organism from becoming oblivious, and speed up the post-commencement recovery process. one of the reasons.

Internal factors that contribute to the occurrence of sports injuries include changes in the behavior of athletes under the influence of inherent characteristics, trends and competitions, or under the influence of adverse external and internal environment. The following internal factors are of particular importance:

1. Fatigue and excessive tiredness (fatigue). In these cases, coordination damage, protective reactions and deterioration of attention are particularly dangerous. In such cases, injury results from the development of mutual discrepancies in the work of antagonistic muscles, resulting in the reduction of movement amplitude and loss of speed and eccentric capacity in performing the action. Disturbed muscle contraction and relaxation of muscles causing muscle breakdownFunctional changes occurring in individuals who are physically insufficiently affected, such as decreased muscle tiredness and depression, decreased force reduction, and relaxation. They make it difficult to act and cause injury. Traumatic injuries may also be caused by the use of methods and means (athletes, treatments, physiotherapy, medicines) that do not comply with physician recommendations to improve the athlete's ability to work and prevent body fatigue.

2. Diseases and other causes, long-term non-sports involve changes in the functional state of the organism and the ability to work. At the same time, muscle strength, durability, reduction in the rate of relaxation and relaxation are difficult to perform complex actions, resulting in injury. If the athlete is unable to attend the training for a certain period of time, he / she can cause dynamic stereotype loss and coordination of movement, and may result in injury.

3. Characteristics of the biomedicine of the bearing motion apparatus and the change in the structure of the biomedicine.

4. Insufficient physical preparation of athletes to perform intensive and complex coordination exercises.

5. Tendency to spastic reductions in muscle and blood vessels (uneven muscle contraction and tension). Most injuries in sport result from shock. In most cases it is to fall to ground, floor, ice, and water. The movement of the amplitude beyond the physiological limit is another mechanism of injury. In other words, they are a wound on the mechanism of weighing and turning.An obstacle to natural action and disturbance of movement control (excessive bumping and muscle tissue or muscle), changes in the structure of biomechanical biomass cause such damage. Consequently, injuries are the result of nonobservance of all rules of sport, including labor protection.

It is desirable to use analytical methods commonly used to predict risk in industrial spheres because of injuries in sports and types of sports, equipment, equipment threats, and harmful factors in training.

Below is a brief description of the key techniques recommended for risk analysis.

1. The "Checklist" and "What if ..., what happens?" Methods or their combination are part of the qualitative risk assessment methodology, based on the study of the conformity of the object to the conditions of use or project safety requirements.

Questions and answers about the learning process, compliance with the safety requirements of the sports facility, and the guidelines for their maintenance are the result of the checklist. The checklist differs from the fact that the results of the "What if ...?" Checkout are the result of the initial data and the consequences of security breaches.

These methods are fairly straightforward (especially in the form of auxiliary forms that facilitate the analysis and presentation of results), does not require much effort (the results can be obtained by one staff within a day) and are effective in examining familiar safety exercises, sports facilities safety is calculated.

2. "Type and Impact Analysis Type" (CTDS) is used for the qualitative analysis of the considered threat (technical equipment or technical equipment). An important aspect of this method is that each hardware (such as a tourniquet, a plug, a public device, a block, an item) or a component of the system (element) has detected a malfunction (type and reason of the infringement) and how the deterioration affects the technical system output.

The analysis of the type and impact of an infection can be expanded to the Type, Criterion, and Criticality Analysis (CTDT). In this case, each type of infringement is divided by the two components of criticality - taking into account 
the probability (or frequency) and weighting of the consequences. The determination of criticality parameters will be required to define the priority of development and security measures.

The results of the analysis are presented in the form of the list of equipment, the type and types of possible disruptions, frequencies, consequences, criticality, detection (signaling, monitoring devices, etc.) and recommendations for risk mitigation.

BTOT, BTOKT methods are typically used to analyze complex technical systems projects or technical solutions. It is carried out by the team of 3-7 specialists for several days and weeks, by a group of specialized professionals (eg, pedagogical technology, training and mentoring trainer, trainer).

3. The Risks and Opportunity Analysis (HIAC) methodology examines the construction of sports facilities and equipment from the point of view of the potential dangers of constructive and technological parameters (reliability, microclimatic temperature, pressure, etc.). In terms of the complexity of the XIQQ and the quality of the results, BTO has a level of BTOKT.

The analysis identifies the potential displacement for each component of the hazard, the cause of their failure and the inhibition of the risk. In the description of departure, "no", "very", "low", "as well", "different", "reverse" and so on. keywords should be used. The use of keywords will help the performers to identify all possible delays.

The analysis results are presented in the custom tables. The risk of expulsion can be determined quantitatively by evaluating the probability and severity of the circumstances under consideration by criterion criteria.

The XIQT method, as well as the identification and separation of risks such as CTDC, helps to identify gaps and errors in security guides, and will further improve them.

4. Practice is known that severe injuries are typically characterized by a combination of unexpected events occurring at different frequencies at different stages of development and development (sports equipment or equipment failure, human error, unacceptable external influences, disorder, intoxication, etc.) . The logical and graphical methods of the "tree of distortion" and the "event tree" analysis are used to determine the cause of the relationship between these events.

The "Tree of breaks " analysis (BSC) identifies the combination of hardware failures, malfunctions, athlete errors and unacceptable external effects that result in a major event (injury). The method is used to analyze potential causes of injury and to calculate its frequency (based on the frequency of the original event)

The "Tree of events" analysis (WTD) is an algorithm for creating a sequence of events that is derived from the main event (traumatic state). It is used to analyze the development of the traumatic event. The frequency of each scenario of development injury is calculated by multiplying the main event frequency by the conditional probability of the final event.

5. The quantitative analysis methods of the hazard are usually carried out by calculating multiple risk indicators, and may include one or more of the above methods (or their results). Quantitative analysis includes the time of the presence of highly qualified experts, sports equipment accident, reliable information, expertise, environmental specificities, weather conditions, athletic spots (spaces, rings, carpets) and other factors to consider.

Quantitative risk analysis enables us to evaluate and compare different risks according to single indicators.

6. Recommendations for the selection of risk analysis methods for the types of activities and activities of the hazardous production facility are presented in Table 2 below (Table 2): "0" - Incompatible analysis method; "+" recommended method; "++" is the most appropriate method.

Methods can be used individually or in combination, such as qualitative analysis methods, which may include quantitative risk criteria (mainly based on expert estimates, for example, the probability of occurrence of the consequences weighted matrix). In the quantitative risk assessment, the results of the qualitative risk analysis should be used as much as possible.

Table 2 Recommendations for the selection of risk analysis methods that cause injuries

\begin{tabular}{|c|c|c|c|c|c|}
\hline \multirow[b]{2}{*}{ Procedure } & \multicolumn{5}{|c|}{ Type of activity } \\
\hline & $\begin{array}{l}\text { Positioning } \\
\text { (Project } \\
\text { Purchases) } \\
\end{array}$ & Developman & Usage in / out & Usage & Reconstruction \\
\hline 1. What is the "What if ....?" & $\begin{array}{ll} \\
\end{array}$ & + & + & + & + \\
\hline 2. The form of the invitation & 0 & + & + & + & + \\
\hline $\begin{array}{l}\text { 3. Risk Analysis and Performance } \\
\text { Analysis }\end{array}$ & 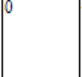 & + & + & $I^{+}$ & H \\
\hline $\begin{array}{l}\text { 4. Types of assesment and analysis of } \\
\text { consequences }\end{array}$ & 0 & + & + & + & + \\
\hline 5.Transition and Event Tree Analysis & 0 & + & + & + & + \\
\hline 6. Quantitative risk analysis & + & + & 0 & + & + \\
\hline
\end{tabular}

The prediction of spores can include "what if ....", "check sheet", "risk and performance", "types and types of impairments", "malfunction and event tree", " use of predictable risks to prevent injuries in sports, equipment, tools, equipment threats and harmful factors during training.

\section{REFERENCES}

1. The Decree of the President of the Republic of Uzbekistan from February 7, 2016 N UP-4947 "On Strategy of Action for Further Development of the Republic of Uzbekistan" // "Khalq Suzi" newspaper 8 February 2017 (6722).

2. Law of the Republic of Uzbekistan "On Physical Training and Sports" (new edition) // Bulletin of the Chambers of the Oliy Majlis of the Republic of Uzbekistan, 2005, No. 9

3. The Law of the Republic of Uzbekistan "On the State Youth Policy" was passed by the Legislative Chamber of August 12, 2016, approved by the Senate on August 24, 2016.

4. Bashkirov V.F. Injury and incidence of the musculoskeletal system in athletes jumpers / Bashkirov V.F., Grachev V.M. // Theory and practice of physical culture. - 1983. - № 2. - p. 47-49.

5. 5.Plotnikov S.G., Maryanovsky A.A. Prediction of injury in athletics with regard to motor asymmetry // Theory and practice of physical culture. - 2009. - № 10.

6. 6.ISO/IEC 31010:2009 "Risk management - Risk assessment techniques". 